\title{
The level of moral competences of pre-service PE teachers - a reason to worry?
}

\author{
Małgorzata Bronikowska ${ }^{1}$, Agata Korcz ${ }^{2}$ \\ ${ }^{1}$ Laboratory of Ethnology of Sport, University of Physical Education, Poznań, Poland; ${ }^{2}$ Department of Didactics of \\ Physical Activity, University of Physical Education, Poznań, Poland
}

\section{Summary}

Study aim: The main purpose of this study was to examine the level of moral competences of 437 pre-service physical education (PE) university students. It was also designed to evaluate the level of moral competency and the correlations with factors (i.e. Parents, Religion, School education, PE teacher, Sport coach, Studies, Media and Peers) potentially influencing moral development in pre-service PE teachers.

Material and methods: The study included data collected in 2017 from 216 male and 221 female students aged $21.5 \pm 1.85$ from the faculty of Physical Education in Poznań, Poland. The students were categorised into three levels of moral competences, after which possible correlations between the factors influencing moral development were examined. The Moral Competence Test (MCT) survey was used to measure the ability to rate arguments by their moral quality. Participants were requested to confront two moral dilemmas and agree or disagree with the statements which were presented to them.

Results: The results suggest that a vast majority of students $(78.7 \%)$ present a very low level of moral competences, and with regard to the factors influencing moral development, the lowest value was attributed to PE teachers. Moderate positive correlations were found between School education and PE teacher, and between Sport coach and PE teacher.

Conclusions: The findings indicate the need for more attention to be paid to moral education in teacher training in PE.

Keywords: Pre-service teachers - Moral competences - Physical education - Teacher education

\section{Introduction}

Parents, sport coaches, and PE teachers have always been concerned about pupils' behaviours during active sporting. Scholars have studied the issue in the general educational setting and how this interferes with the effectiveness of sport education [25], as well as in physical activity (PA) contexts $[40,22]$. The findings are equivocal - some studies suggest that PA and pro-social behaviour in pupils improves as a result of engagement in PE and sport [8], even more so when receiving support from PE teachers [9], while in some circumstances behaviour actually worsens [4]. Bailey et al. [3] claim that school $\mathrm{PE}$ and sport has the potential to contribute to the whole development of young people in 4 domains - physical, social, affective and cognitive - though in the case of social and cognitive effects benefits are mediated by environmental and contextual factors. Drewe [18] points at the connection of moral and physical spheres, which seems logical when PE turns into an arena for practising moral behaviour and the teacher provides a context for respect between peers in the mutual struggle to better themselves. But when a PE teacher does not value moral development of their pupils it may turn out to be a problem. Therefore, it seems interesting to investigate the level of moral competences of PE students before they start their service with children in schools.

In education policies in most countries school should equip pupils with moral competences [23]. But at the same time educational programmes reveal that school subjects undertaking some aspects of moral education are unilaterally geared to raising the knowledge of moral conceptions, which are easy to be tested in students, but they may have little in common with peoples' behaviour [30].

Sanger and Osguthorpe [39] state that prospective teachers commonly believe that teaching is morally significant work and that moral aspects are common reasons for studying towards joining the teaching profession. But the level of moral competences of those pre-service teachers 
is less well known. Some findings [17] indicate that moral reasoning levels of pre-service and in-service teachers are relatively low. From Lind [30] we only learn that the ethics teachers should be able to promote the responsibility and autonomy of the individual by applying themselves to the fundamental moral principles in teaching students, in the same manner as PE teachers must be well prepared to demonstrate any recommend exercise to students. It seems to be a simplification of PE teachers' responsibilities in sound development of children. Nevertheless, despite cross-curriculum goals and the motivation of prospective teachers of all subjects, it is often a little more expected of PE and school sport teachers to deliver moral education than it is of other teachers since they (PE teachers) have a wider range of means and ways to positively affect pupils' moral development, albeit through physical effort [18].

Carr [12] asks the more ambiguous question whether the teacher of PE may be rightly regarded as a moral educator and suggests that the potentially affirmative answer is due to the virtue of being a teacher rather than an expert on giving instructions in PA. Shields and Bredemeier [40] consider PE as the most fertile ground for children's socio-moral and character development - when compared to other PAs and competitive sports - but Carr [12] argues against this. He claims that PE, just like any other school subject, does not qualify as a form of moral education. However, this does not automatically mean that moral education cannot take place during these classes through, for example, the cultivation of moral attitudes or development of moral character [12]. Scholars have also emphasized that moral development does not occur automatically but depends on the PE teacher [3]. Jones [24] believes that $\mathrm{PE}$ teachers may be considered as a role model for pupils and therefore set an example by demonstrating moral virtues during PE lessons, but not before they realize and learn themselves what qualities they are trying to teach to children and why. Arnold [2] highlights that it is unlikely that moral values in sport can be effectively taught unless teachers show a commitment to such values themselves.

Chen and Ennis [14] claim that PE teachers present the 'disciplinary mastery' orientation focusing on developing performance proficiency in sport skills and understanding of performance-related knowledge. But Green [21] sees orientation of PE teachers as an 'amalgam' of teachers' subconscious predispositions and practical situations in which those teachers found themselves. How then do PE teachers play a modelling role? Sanders [37] indicates that role modelling is rarely used as an explicit teaching method, and only a very small percentage of pupils consider teachers as role models. Interestingly, Carr [13] believes that moral education has more to do with the character and virtues of the specific PE teacher, rather than any particular didactic skills they possess. Therefore PE teachers' standards should be a significant part of the process of moral education. Jones [24] claims that virtues should be embodied in the character of a teacher so they can be applied directly in the teaching process, in the 'heat' of the action, not post-hoc or hypothetically. Unfortunately, a study by Theodoulides [43] indicates that some PE teachers perform instrumental actions or promote behaviours in their pupils aimed at winning, sometimes leading to unsporting, even unfair play, and tend to allow and accept rule breaking and gamesmanship, specifically during extra-curricular sport activities [13]. Carr [13] suggests that there are conflicts and contradictions between the moral values pupils learn in games lessons and those they are taught also during competitive inter-school matches. It is hard to believe that those teachers do not realize such behaviour is inappropriate (in terms of moral education), but perhaps they might consider it less important than the final outcome of sport education for them - winning a game.

Therefore, more empirical studies, which examine how PE teachers can facilitate the development of moral attitudes in pupils, are needed.

Parents are believed to better facilitate moral development in the early stages through more frequent domainspecific and appropriate feedback and developmentally sensitive reasoning than peers and teachers can provide [41]. Also parenting style seems to be clearly related to post-conventional reasoning in young adolescents, which supports the importance of family (moral) atmosphere [7]. However, later in life some weight of the process is shifted to the schooling process and to teachers, but how this moral development of a child is continued in school and whether there is any connection between the two most influential factors - parents and teachers - is less known.

Koh et al. [26] argue that values training programmes for PE teachers and sport coaches should involve parents more closely by having them take on important roles in the values learning process of PE pupils, but this sounds rare. The determinants of moral competence of pre-service PE teachers must be identified through a theoretical framework.

The Moral Competence Test (MCT) [31] used in the study is based on Kohlberg's structural-developmental theory of morality, which assesses a person's moral competence, defined as the ability to resolve problems and conflicts on the basis of one's moral principles through deliberation and discussion, instead of through violence, deceit, or bowing down to others [31]. MCT measures the ability to rate arguments by their moral quality rather than other criteria [31]. Kohlberg [27] believes that moral development is affected by the experiences of an individual acquired in various settings and contexts. He analyzed moral capacity and moral reasoning at two layers, referring, on one hand, to structure as to the form of reasoning, and to the specific norms, values, and beliefs on the other. 
In Kohlberg's works, a three-level model is used [27], consisting of a sequence of 6 stages of moral development. An individual develops morally from the pre-conventional level through conventional to post-conventional levels. Although not everyone reaches the highest stages of moral development in their life, it is expected that teachers should act and conduct their behaviours and didactic process with higher (post-conventional) rather than lower levels of moral reasoning. Understanding what motivates preservice PE teachers in their moral behaviours and whether they behave well (particularly in a teaching/learning process) because they either expect a reward for that or comply with their internal moral consistency, might be a crucial factor for the future of teaching moral education through $\mathrm{PE}$ and school sport. The MCT scoring system $(C$-index $)$ takes into account the overall pattern of a person's moral competency and thus provides a reliable evaluation of the state of moral development. Individuals can score high on the $C$-index only when they show moral consistency in the judging of pro and contra arguments in the test, which is a characteristic of those with better cognitive structures and the capacity to value opposing viewpoints. A lack of these skills and no moral consistency will automatically lead to a low score.

Little is known about how pre-service PE teachers judge their moral attitudes and what influences their moral competences, and as they will shortly begin their work in the education system, more information is needed. Thus, based on the above-mentioned prerequisites we designed a study to explore and evaluate the level of moral competences of pre-service PE teachers and the correlations with the factors Parents, Schooling, PE teachers, Sport coaches, Religion, Media and the influential role of Peers in three level groups of moral competences.

\section{Material and methods}

\section{Participants and procedure}

The study included data collected in 2017 from 216 male and 221 female students aged $21.5 \pm 1.85$ from the faculty of Physical Education, where the survey was performed in every dean group at the faculty. Students were in years one to five of their studies at the University of Physical Education (see Table 1).
Participation in the survey was voluntary and the total return rate ranged from $56 \%$ to $76 \%$ depending on the year of study (see Table 1). Questionnaires were completed in whole-class groups during a regular academic class in quiet classroom conditions and took approximately 30 minutes to complete.

\section{Moral competences}

To measure moral competences Lind's MCT was used [31]. For the purpose of this study, a Polish validated and certified version was used [34]. Participants were requested to confront two moral dilemmas and agree or disagree with the statements which were presented to them. Students responded to a 9-point Likert-type scale, from - 4 (totally disagree) to +4 (totally agree). Every dilemma had 12 statements (6 in favour and 6 against the proposed behaviour). Each statement corresponded to 1 of 6 stages of moral development (as presented by Kohlberg [27]). The summarized score (C-Index) is computed and ranges from 1 to 100 . It actually measures a person's ability to assess an argument based on their moral quality or, in simpler terms, the degree to which a person allows their personal judgments to be affected by moral concerns or principals rather than their personal opinions and constructions. Scores below 9 are considered to be an extremely low, scores 10 to 19 are considered low, scores 20 to 29 are considered medium, 30 to 39 are considered high, 40 to 49 very high, and above 50 extremely high. For the purpose of the study the group was divided into three levels of moral competences: low and very low $(\leq 19)$, medium (20-29), and high and very high ( $\geq 29)$.

\section{Moral influence scale}

For examining the role of different factors influencing moral competences an 8-item scale was developed specifically for the purpose of the study by the authors themselves. The scale constituted the question 'What has influenced your moral competences?' with 8 items: Religion, School education, Parents, PE teacher, Sport coach, Peers, Media, and Studies. The Likert scale ranged from $1=$ not at all to $5=$ very much. The Cronbach's alpha coefficient value was 0.72 .

\section{Statistical analyses}

Descriptive statistics were obtained and are presented in Table 2, with the groups divided by the level of moral

Table 1. Number of pre-service PE teachers examined in each academic year of study

\begin{tabular}{lcccccc}
\hline & Total & Year 1 & Year 2 & Year 3 & Year 4 & Year 5 \\
\hline Male students number & 216 & 60 & 44 & 26 & 48 & 38 \\
Female students number & 221 & 49 & 38 & 42 & 47 & 45 \\
Total number/number of surveyed & $663 / 437$ & $143 / 109$ & $130 / 80$ & $125 / 70$ & $133 / 95$ & $132 / 83$ \\
\% of year total & $65.9 \%$ & $76.0 \%$ & $61.5 \%$ & $56.0 \%$ & $71.4 \%$ & $62.9 \%$ \\
\hline
\end{tabular}


competences. To compare differences between the groups of moral competence the Kruskal-Wallis test with significance set at $\mathrm{p}<0.05$ was carried out.

It was also examined whether, and to what extent, different factors influencing moral competences were correlated. To test the relationships between variables a Spearman correlation test was used with the value of correlation strength: $\leq 0.39$ weak; $0.40-0.59$ moderate, and $\geq 0.60$ strong. Significance was denoted by $\mathrm{p}<0.05$. Statistical analysis was carried out using Statistica 13.0 software.

\section{Ethics}

The research was conducted according to the principles of the Declaration of Helsinki. Students were informed about the anonymous and voluntary nature of their participation, that the study records would be kept confidential, and that their individual contributions would be unidentifiable in the final report. The study protocol was approved by the Local Bioethics Committee (decision no. 908/16).

\section{Results}

There was a significant difference between the groups presenting a low level of moral competences and the two other groups of medium and high levels $(\mathrm{p}<0.05)$ in the $C$-index, with the low competence group scoring at a very low 8.6 point average level, and the high competence group gaining 37.6 points on average. Those who presented the highest level of competences formed a relatively small group, constituting just $5.9 \%$ of the total sample (see Table 2). The biggest group (78.7\%) presented a low level of moral competences. In other variables, significant differences were observed in the PE teacher factor (scores of low and medium level of competence groups were higher than the other group with $\mathrm{p}<0.05)$, and a similar relation was noted for the Media factor - significantly higher importance of that factor was indicated by low and medium groups of moral competence than the group of high competence. Among other variables, mean scores did not differ significantly between the groups. What is worth noting is the reasonably high mean scores credited to Parents (mean score above 4 on a scale of 1 to 5) by all three groups. The lowest average significance of the influence on moral development was ascribed to Media and PE teacher in all three groups.

Table 3 presents correlation values for the three levels of moral competence groups. The analysis showed some interesting patterns. There was a moderate correlation between PE teacher and School education factors in all three groups observed (for low competence group $r=0.43$; for medium competence group $r=0.43$, and for high competence group $r=0.47$ ). Similarly, a moderate correlation was noted between Media and Peers in the low competence group, $\mathrm{r}=0.46$, and the medium competence group, $r=0.43$, with a strong correlation in the high competence group, $\mathrm{r}=0.68$. Also the Studies factor correlated moderately with School education in all three groups, respectively $\mathrm{r}=0.43, \mathrm{r}=0.44$, and $\mathrm{r}=0.47$. The Sport coach factor correlated with $P E$ teacher in the medium competence group, $\mathrm{r}=0.49$, and the high level of competence, $\mathrm{r}=0.53$, and in the low level group the correlation was approaching moderate, $r=0.37$. Apart from that, a moderate correlation $(\mathrm{r}=0.51)$ was found in the medium moral competence group between Peers and PE teacher factors. In the group with the highest moral competence level moderate correlations were observed between Media and School education $(\mathrm{r}=0.52)$, Studies and Peers $(\mathrm{r}=0.56)$, and Studies and Media $(\mathrm{r}=0.48)$. From among the factors provided there were weak correlations found with $C$-index only in the medium level group and all of them were negative (with School education $\mathrm{r}=-0.33, P E$ teacher $\mathrm{r}=-0.24$,

Table 2. Descriptive characteristics of variables (mean $\pm \mathrm{SD}$ ) of pre-service PE teachers

\begin{tabular}{lcccc}
\hline \multicolumn{3}{c}{ Level of moral competences } \\
\hline Variable & Low $\mathrm{n}=344$ & Medium $\mathrm{n}=67$ & High $\mathrm{n}=26$ & p-value (post hoc) \\
\hline C-Index level & $8.6 \pm 5.21$ & $23.4 \pm 2.85$ & $37.6 \pm 6.77$ & 1 vs $2,3<0.05$ \\
Religion & $3.2 \pm 1.47$ & $3.0 \pm 1.59$ & $2.7 \pm 1.82$ & Ns \\
School education & $3.1 \pm 1.16$ & $2.9 \pm 1.19$ & $2.5 \pm 1.30$ & Ns \\
Parents & $4.1 \pm 1.01$ & $4.1 \pm 1.10$ & $4.1 \pm 1.03$ & Ns \\
PE teacher & $2.7 \pm 1.26$ & $2.7 \pm 1.33$ & $2.1 \pm 1.44$ & 1,2 vs $3<0.05$ \\
Sport coach & $3.2 \pm 1.32$ & $3.5 \pm 1.21$ & $3.1 \pm 1.32$ & Ns \\
Peers & $2.9 \pm 1.12$ & $3.1 \pm 1.03$ & $2.5 \pm 1.10$ & Ns \\
Media & $2.2 \pm 1.21$ & $2.1 \pm 1.22$ & $1.5 \pm 1.21$ & 1,2 vs $3<0.05$ \\
Studies & $3.0 \pm 1.15$ & $3.0 \pm 1.25$ & $2.5 \pm 1.17$ & Ns \\
\hline
\end{tabular}

Ns - non significant 
Table 3. Correlation matrix according to the level of moral competences in pre-service PE teachers

\begin{tabular}{|c|c|c|c|c|c|c|c|c|c|}
\hline Variable & C-index & Religion & $\begin{array}{c}\text { School } \\
\text { education }\end{array}$ & Parents & $\begin{array}{c}\mathrm{PE} \\
\text { teacher }\end{array}$ & $\begin{array}{l}\text { Sport } \\
\text { Coach }\end{array}$ & Peers & Media & Studies \\
\hline \multicolumn{10}{|c|}{ Low level of Moral Competences $(n=344)$} \\
\hline C-index & & -0.06 & -0.01 & -0.04 & -0.01 & -0.02 & -0.04 & -0.07 & -0.02 \\
\hline Religion & & & 0.26 & 0.25 & 0.12 & 0.14 & 0.06 & 0.04 & 0.03 \\
\hline School educ. & & & & 0.32 & $0.43 *$ & 0.21 & 0.23 & 0.23 & $0.43 *$ \\
\hline Parents & & & & & 0.13 & 0.17 & 0.13 & -0.02 & 0.16 \\
\hline PE teacher & & & & & & $0.37^{*}$ & 0.20 & 0.13 & 0.28 \\
\hline Sport coach & & & & & & & 0.24 & 0.16 & 0.23 \\
\hline Peers & & & & & & & & $0.46^{*}$ & 0.23 \\
\hline Media & & & & & & & & & 0.25 \\
\hline \multicolumn{10}{|l|}{ Studies } \\
\hline \multicolumn{10}{|c|}{ Medium level of Moral Competences $(n=67)$} \\
\hline C-index & & -0.01 & -0.33 & -0.06 & -0.24 & -0.08 & -0.11 & -0.22 & -0.33 \\
\hline Religion & & & 0.21 & -0.03 & 0.09 & 0.21 & 0.01 & 0.20 & 0.10 \\
\hline School edu. & & & & 0.27 & $0.43 *$ & 0.11 & 0.28 & 0.37 & $0.44 *$ \\
\hline Parents & & & & & 0.34 & 0.08 & 0.10 & 0.27 & 0.09 \\
\hline PE teacher & & & & & & $0.49 *$ & $0.51 *$ & 0.36 & 0.32 \\
\hline Sport coach & & & & & & & 0.17 & 0.09 & 0.03 \\
\hline Peers & & & & & & & & $0.43 *$ & 0.32 \\
\hline Media & & & & & & & & & 0.30 \\
\hline \multicolumn{10}{|l|}{ Studies } \\
\hline \multicolumn{10}{|c|}{ High level of Moral Competences $(n=26)$} \\
\hline C-index & & 0.11 & 0.06 & 0.06 & 0.01 & -0.03 & 0.23 & 0.23 & 0.16 \\
\hline Religion & & & -0.01 & 0.07 & 0.12 & 0.38 & 0.01 & -0.07 & -0.25 \\
\hline School educ. & & & & -0.03 & $0.47 *$ & 0.22 & 0.33 & $0.52 *$ & $0.47 *$ \\
\hline Parents & & & & & 0.14 & 0.11 & -0.04 & 0.09 & 0.04 \\
\hline PE teacher & & & & & & $0.53 *$ & 0.21 & 0.23 & 0.28 \\
\hline Sport coach & & & & & & & -0.05 & 0.06 & 0.09 \\
\hline Peers & & & & & & & & $0.68 *$ & $0.56^{*}$ \\
\hline Media & & & & & & & & & $0.48 *$ \\
\hline Studies & & & & & & & & & \\
\hline
\end{tabular}

$*_{-} \mathrm{p}<0.05$; correlation $\leq 0.39$ weak, $0.40-0.59$ moderate, and $\geq 0.60$ strong.

and Studies $\mathrm{r}=-0.33)$. There were no significant correlations with $C$-index in any other group.

\section{Discussion}

Our findings suggest that the majority $(78.7 \%)$ of examined pre-service PE teachers present rather low levels of moral competences, with a mean $C$-index of 8.4 points. According to Lind [31], only 5.9\% represented the level of competences enabling them to qualify as having the highest level of moral competences. As for the remainder $(15.4 \%)$, they were qualified as individuals with a medium level of moral competences. These findings might come as additionally depressing news when we realize that the examined participants were pre-service teaching students of the school subject (PE) that is traditionally associated with forming and influencing the moral development of school-aged children in the most fundamental way, i.e., through sporting experience. In these terms, an even more 
downbeat commentary might be found in Rest's [35] statement that moral development increases until early adulthood and may reach a plateau then. This means that future PE teachers are not well prepared to deliver moral education in their daily practical activities.

Higher education has a major contribution to make to the moral and ethical standards of future professionals [16]. Educators indicate that the level of moral competences of students have declined in many areas $[6,20$, 11, 36]. Buzkova and Sikorova [11] reported a mean C-index of 14.2, whereas Rzymska [36] reports that the mean $C$-index value changed during the duration of studies from 12.8 points in the first year to 11.4 in the fourth year. Samanci [37] reports the $C$-index score of pre-service primary teachers to be around 16 points, which is similar to pre-service biology students. In a study on youths but not students (mean age 24.3), Chrenkova and Sukolova [15] also reported a rather low $C$-index value (15.7), which is in line with our findings with regard to the whole group mean value (12.6). Thus, it is possible that these values are characteristic of today's young adults, rather than outliers, and if so, this is a comment on how school education has failed to suitably equip these young people with moral competences. Some rightly point out that this should be up to the ethics education, but ethics education probably 'owes' its ineffectiveness partly to the fact that it is often separated from the rest of the curriculum in schools. In its present form, there is no room for open discussions during the classes, which does not teach critical reflection [28]. The results of Samanci [37] indicate a positive and statistically significant relationship between moral judgment competences and critical thinking abilities of pre-service primary and biology teachers when these issues are interwoven in the teaching curricula. It indicates that critical thinking and moral judgment competences have a key role in shaping and improving teaching attitudes. A study by Stephens [42] on over a thousand American Millennial generation students showed the mean $C$-index value to be 17.1 points, and a significant correlation was noted between moral judgment competence and parental attachment, indicating the strong fostering role of parents in the moral development of their children. However, it was observed that when a student moves from secondary to academic education, they often disengage from their parents and want to become autonomous people.

One interesting observation made in our study came from analyzing the correlation scores in factors influencing the moral development of the examined PE students. Among those factors which were attributed the highest values were Parents. At the opposite end of the scale, the lowest values were assigned to Media, but here, moderately significant correlations were found with Peers in all three groups. The correlation between Education and $\mathrm{Me}$ dia was extended in the group with the highest level of moral competences in factors such as Studies and Peers, and Studies and Media, which, together with the highest $C$-index, may indicate that students from that group use their environment more cautiously, and with more critical reflection.

A significant difference was observed between the low and medium groups of moral competences and the one with the highest $C$-index in how they perceived the role of PE teachers in influencing their moral development. Students from the first two groups valued it higher than the ones who presented the highest level of moral competence. Moderate correlations were found with School education in all three groups. Unfortunately, it shows that the students do not give much credence to their PE teachers as moral educators, and this has to be changed. Nowadays, when personal interactions are increasingly conducted through social media and smart phones, especially PE offers the opportunity to "navigate challenging tasks through face-to-face negotiation and discussion' [10]. As Butler [10] suggests, PE gives a context where it becomes difficult to smooth over and ignore such problems as unfairness and injustice.

As far as we are aware, there are not many studies using moral MCT in PE teachers [37]. However, teaching moral behaviour in PE is one of the educational goals of the subject and thus an indispensable part of the teacher's conduct. Agbunga, Xiang, and McBride [1] found a positive association of performance-approach and performance-avoidance goals set by the PE teacher with self-reported disruptive behaviours, whereas a negative relation was found with mastery-goal and engagement. However, it could be claimed that it is not only a matter of what instructions and content are being taught in the PE context but how they are taught too. It is the ethos, set of virtues, and the kind of sporting experience that PE teachers create in a teaching-learning process that provides a framework for the moral development of pupils $[2,10]$. Bailey et al. [3] point out that the participation in PE and sport contributes positively to a child's social development depending on the actions and interactions of teachers and coaches with the children and on whether or not these professionals achieve their potential in this area. The generally low level of moral competences of the relatively large number of examined pre-service PE teachers may serve as a commentary on the outcome of the effectiveness of the present education system and also as an indicator of the future. Interestingly, the role of a sport coach was given more value in all three groups than the role of a PE teacher, but this might be related to the fact that when one decides to undertake sport it is usually done out of free will, unlike in compulsory PE.

Moral development takes place through experiencing [30]. Kolhberg [27] drew attention to 'role-taking' experiences which enhance moral development, and teachers, 
specifically PE teachers, are often faced with such social situations in which they have to consider points of view of others as well as their level of capabilities. The most promising contexts for developing moral attitudes and behaviours are those among suitably trained PE teachers and coaches who focus on situations that arise naturally through activities, by asking questions of students and by modelling appropriate responses through their own behaviour [19]. However, it ought to be remembered that PE teachers often lack formal training in the teaching of moral development, and yet it is less known what influences their own level of moral competences and sets of values, and how it is associated with the ways they organize and operationalize it in a single lesson [23]. However, it seems that it is not only an issue of proper training. Jacobs et al. [23] point out that there are some PE teachers who actively plan PE lessons aimed at developing moral skills in their pupils, even though they were not trained for it. The authors [23] recommended the use of a contextually based bottom-up approach that allows individuals to design activities to develop moral skills that are meaningful to pupils rather than a standardized curriculum. Meanwhile, in the study of Koh et al. [26] where an instructional programme was designed to teach values through $\mathrm{PE}$ and sport, it was indicated that adult learners must be trained appropriately, guided by establish theories, such as Kolb's theory of experimental learning.

Some of the findings and differences between the groups of moral competences could be explained by various mediating factors that influenced the individual patterns of upbringing, as well as how these students were socialized through and in sport [23], and also in the family setting. This should become a line of further studies in this area.

Another interesting finding is the role of Religion, which was ascribed a similar value in influencing one's moral development as School education or Sport coach. This is quite an interesting observation in Poland, a country known for its strong Catholic roots. Surprisingly, no correlation with other factors was found. This could be an effect of the democratic transformation of the last 25 years in the country [5]. It is currently observed that the Church is potentially loosening its traditional ties with the young generations.

Another issue is that the MCT test might have been so abstract and unrelated to the pre-service PE teachers face in their daily learning/teaching routine and therefore the $C$-index scores are low. Mouratidou, Chatzopoulos and Karamavrou [32] introduced the MCT in PE, indicating its adequate construct validity and positive, although weak, correlation with the original MCT. However, Lind [29] had advocated interpreting it with great care as, he argued, the test is targeted at a specific group, physical educators. In our research, we decided to focus on that specific group of educators and to use the original MCT, but perhaps these two instruments should be combined in further studies.

We are aware that there are other measures for moral development, for example the Defining Issues Test (DIT), which might be more sensitive to race, religion and social differences, but these factors are not an issue in Poland. The DIT measures more the beginnings of non-verbal intuitive moral understanding, whereas the MCT measures predominantly higher levels of verbal understanding [33], and as such seemed more suited for the group. We take it as one of the limitations of the study, as well as the cross-population nature of the study and the possibility that the level of moral competence of pre-service PE teachers has always been low (there is a research gap in this area). Also, the voluntary nature of the participation could have been an issue: although the participation rate was high, some students opted not to participate in the survey. To be sure, the key strengths of the study are the total number of students examined, the equal representation of each academic year, and the balanced proportion of male and female students.

\section{Conclusions}

Thus far, pre-service PE teacher education lacks proper training in pedagogically effective moral skills and tasks. The low level of moral competences for the majority of examined students raises concerns for the quality of moral education delivered to school children. Furthermore, the low relevance attributed to PE teachers for the influence of moral development by the examined pre-service PE teachers is a key finding.

All these aspects should direct our interest in designing educational courses which pay more attention to moral matters in prospective teacher education, for example moral task dilemmas involving the field of sport experience should be added to the programmes.

\section{Conflict of interest: Authors state no conflict of interest.}

\section{References}

1. Agbuga B., Xiang P., McBride R. (2010) Achievement goals and their relations to children's disruptive behaviors in an after-school physical activity program. J. Teach. Phys. Educ., 29(3): 278-294. DOI: 10.1123/ jtpe.29.3.278.

2. Arnold P.J. (2001) Sport, moral development, and the role of the teacher: Implications for research and moral educatiosn. Quest, 53(2): 135-150. DOI: 10.1080/00336297.2001.10491734.

3. Bailey R., Armour K., Kirk D., Jess M., Pickup I., Sandford R. (2009) The educational benefits claimed for 
physical education and school sport: an academic review. Research Papers in Education, 24(1): 1-27. DOI: 10.1080/02671520701809817.

4. Beller J. Stoll S. (1995) Moral reasoning of high school students athletes and general students: an empirical study versus personal testimony. Pediatr. Exerc. Sci., 7: 352-363.

5. Borowik I. (2002) The Roman Catholic Church in the process of democratic transformation: The case of Poland. Social Compass, 49(2): 239-252. DOI: 10.1177/0037768602049002008.

6. Bosco S.M., Melchar D.E., Beauvais L.L., Desplaces D.E. (2010) Teaching business ethics: The effectiveness of common pedagogical practices in developing students' moral judgment competence. Ethics and Education, 5(3): 263-280. DOI: 10.1080/17449642.2010.533049.

7. Boyes M.C. Allen S.G. (1993) Styles of parent-child interaction and moral reasoning in adolescents. MerrillPalmer Quarterly, 39(4): 551-570.

8. Bronikowski M. (2010) Is sense of coherence needed to keep youth physical active? Medicina dello Sport, 63(4): 465-483.

9. Bronikowski M., Bronikowska M., Glapa A. (2016) Do they need goals or support? A report from a goal-setting intervention using physical activity monitors in youth. Int. J. Environ. Res. Public Health, 13: 914-926. DOI: 10.3390/ijerph13090914.

10. Butler J. (2016) Playing fair. Champaign, IL: Human Kinetics.

11. Bužgová R. Sikorová L. (2013) Moral judgment competence of nursing students in the Czech Republic. Nurse Education Today, 33(10): 1201-1206. DOI: 10.1016/j. nedt.2012.06.016.

12. Carr D. (1998) What moral educational significance has physical education? A question in need of disambiguation. Ethics and sport, pp. 119-133.

13. Carr D. (2003) Character and moral choice in the cultivation of virtue," Philosophy, 78(2): 219-232. DOI: 10.1017/S0031819103000251.

14. Chen A. Ennis C.D. (1996) Teaching Value Laden Curricula in Physical Education. J. Teach. Phys. Educ., 15(3): 338-354.

15. Chrenková P. Šukolová D. (2017) Nevera Vo Vzt’ahu K Morálnemu Usudzovaniu - Infidelity In Relation To Moral Reasoning. In: Lukas Pitel (ed.) Socialne Problemy a osobnost, Ústav experimentálnej psychológie, pp. 186-193. Centrum spoločenských a psychologických vied SAV: Bratislava.

16. Corcoran R.P. O'Flaherty J. (2016) Examining the impact of prior academic achievement on moral reasoning development among college students: A growth curve analysis. J. Moral Educ., 45(4): 433-448. DOI: 10.1080/03057240.2016.1230051.

17.Cummings R., Harlow S., Maddux C. (2007) Moral reasoning of in-service and pre-service teachers: a review of the research. J. Moral Educ., 36(1): 67-78. DOI: $10.1080 / 03057240601185471$.

18. Drewe S.B. (2000) The logical connection between moral education and physical education. J. Curriculum Stud., 32(4): 561-573. DOI: 10.1080/00220270050033628.

19. Ewing M.E., Gano-Overway L.A., Branta C.F., Seefeldt V.D. (2002) The role of sports in youth development. Paradoxes of youth and sport, pp. 31-47.

20. Feitosa H.N., Rego S., Bataglia P.U.R., Rego G., Nunes R. (2013) Moral judgment competence of medical students: a transcultural study. Adv. Health Sci. Educ., 18(5): 1067-1085. DOI: 10.1007/s10459-013-9449-5.

21. Green K. (2000) Exploring the everyday 'philosophies' of physical education teachers from a sociological perspective. Sport Educ. Soc., 5(2): 109-129. DOI: 10.1080/713696029.

22. Hsu W.T., Li H.H., Pan Y.H. (2017) Student Misbehavior in Physical Education: The Role of 2x2 Achievement Goals and Moral Disengagement. J. Sports Sci. Med., 16: 302-310.

23. Jacobs F., Knoppers A., Webb L. (2013) Making sense of teaching social and moral skills in physical education. Phys. Educ. Sport Pedagogy, 18(1): 1-14. DOI: 10.1080/17408989.2011.621118.

24. Jones C. (2005) Character, virtue and physical education. Eur. Phys. Educ. Rev., 11(2): 139-151. DOI: 10.1177/1356336X05052893.

25. Kaplan A., Gheen M., Midgley C. (2002) Classroom goal structure and student disruptive behavior. Brit. J. Educ. Psychol., 72(2): 191-211. DOI: 10.1348/000709902158847.

26. Koh K.T., Ong S.W., Camiré M. (2016) Implementation of a values training program in physical education and sport: Perspectives from teachers, coaches, students, and athletes. Phys. Educ. Sport Pedagogy, 21(3): 295-312. DOI: $10.1080 / 17408989.2014 .990369$.

27. Kohlberg L. (1976) Moral stages and moralization. The cognitive-developmental approach. In: T. Lickona (ed.) Moral development and behaviour. Theory, research and social issues, pp. 31-53, New York: Holt, Rinehart and Winston.

28. Lind G. (2000) The importance of role-taking opportunities for self-sustaining moral development. J. Res. Educ., 10(1): 9-15.

29. Lind G. (2009) A Note of Caution about the Moral Judgment Test in Physical Education (MJT-PE). Psychological reports, 105(3): pp. 886-888. DOI: 10.2466/ PR0.105.3.886-888.

30. Lind G. (2011) Moralerziehung. In: E. Kiel, K. Zierer (eds.) Basiswissen Unterrichtsgestaltung, pp. 51-62, Schneider Verlag Hohengehren Baltmannsweiler: Copyrights by $\mathrm{G}$. Lind.

31. Lind G. (2016) Accessed June 3 2018. https://www.unikonstanz.de/ag-moral/mut/mjt-engl.htm. 
32. Mouratidou K., Chatzopoulos D., Karamavrou S. (2008) Validity study of the moral judgment test in physical education: development and preliminary validation. Percept. Mot. Skills, 106(1): pp. 51-62. DOI: 10.2466/ pms.106.1.51-62.

33. Narvaez D. Bock T. (2002) Moral schemas and tacit judgement or how the Defining Issues Test is supported by cognitive science. J. Moral Educ., 31(3): 297-314. DOI: https://doi.org/10.1080/0305724022000008124.

34. Nowak E. (2008) Validation of the Polish Version of the Moral Judgment Test (MJT). Accessed June 3 2018, https://www.uni-konstanz.de/ag-moral/mut/validation/ MJT-polish-2008-validation-study.pdf.

35. Rest J. R (1979) Development in judging moral issues. Minneapolis: Minnesota Press.

36. Rzymska I. Musielak M. (2011) Evaluation of changes in moral preferences among midwifery students during university studies. Nowiny Lekarskie, 80(4): 272-276.

37. Samanci N.K. (2015) A study on the link between moral judgement competences and critical thinking skills. Int. J. Environ. Sci. Educ., 10(2): 135-153. DOI: 10.12973/ ijese.2015.236a.

38. Sanderse W. (2013) The meaning of role modelling in moral and character education. J. Moral Educ., 42 (1): 28-42. DOI: 10.1080/03057240.2012.690727.
39. Sanger M.N., Osguthorpe R.D. (2013) Modeling as moral education: Documenting, analyzing, and addressing a central belief of pre-service teachers. Teaching and Teacher Education, 29: 167-176. DOI: 10.1016/j. tate.2012.08.002

40. Shields D.L., Bredemeier B.J. (1995) Character development and physical activity. Human Kinetics, Champaign: USA.

41. Smetana J.G. (1999) The role of parents in moral development: A social domain analysis. J. Moral Educ., 28(3): 311-321. DOI: 10.1080/030572499103106.

42. Stephens D.G. (2009) A correlational study on parental attachment and moral judgment competence of millennial generation college students," Doctoral dissertation. University of Nebraska-Lincoln. Accessed June 32018.

43. Theodoulides A. ( 2003) I would never personally tell anyone to break the rules, but you can bend them: Teaching moral values through team games. Eur. J. Phys. Educ., 8(2): 141-159.

\section{Received 07.09.2018 \\ Accepted 08.01.2019}

(C) University of Physical Education, Warsaw, Poland 